\title{
Flibe Coolant Cleanup and Processing in the HYLIFE- II Inertial Fusion Energy Power Plant
}

R.W. Moir

March 23, 2001

U.S. Department of Energy

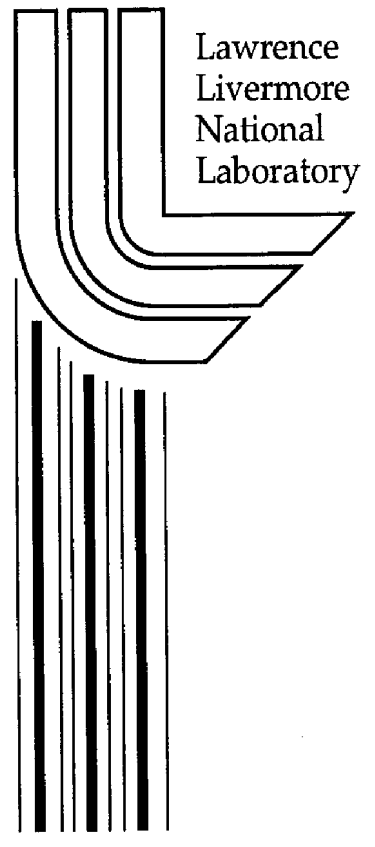




\section{DISCLAIMER}

This document was prepared as an account of work sponsored by an agency of the United States Government. Neither the United States Government nor the University of California nor any of their employees, makes any warranty, express or implied, or assumes any legal liability or responsibility for the accuracy, completeness, or usefulness of any information, apparatus, product, or process disclosed, or represents that its use would not infringe privately owned rights. Reference herein to any specific commercial product, process, or service by trade name, trademark, manufacturer, or otherwise, does not necessarily constitute or imply its endorsement, recommendation, or favoring by the United States Government or the University of California. The views and opinions of authors expressed herein do not necessarily state or reflect those of the United States Government or the University of California, and shall not be used for advertising or product endorsement purposes.

This work was performed under the auspices of the U. S. Department of Energy by the University of California, Lawrence Livermore National Laboratory under Contract No. W-7405-Eng-48.

This report has been reproduced

directly from the best available copy.

Available to DOE and DOE contractors from the

Office of Scientific and Technical Information

P.O. Box 62, Oak Ridge, TN 37831

Prices available from (423) 576-8401

http://apollo.osti.gov/bridge/

Available to the public from the

National Technical Information Service

U.S. Department of Commerce

5285 Port Royal Rd.,

Springfield, VA 22161

http://www.ntis.gov/

OR

Lawrence Livermore National Laboratory

Technical Information Department's Digital Library

http://www.llnl.gov/tid/Library.html 


\title{
Flibe coolant cleanup and processing in the HYLIFE-II inertial fusion energy power plant
}

\author{
R. W. Moir
}

March 23, 2001

\begin{abstract}
In the HYLIFE-II chamber design, a thick flowing blanket of molten-salt $\left(\mathrm{Li}_{2} \mathrm{BeF}_{4}\right)$ called flibe is used to protect structures from radiation damage. Since it is directly exposed to the fusion target, the flibe will absorb the target debris. Removing the materials left over from target explosions at the rate of $\sim 6 / \mathrm{s}$ and then recycling some of these materials poses a challenge for the inertial fusion energy power plant. The choice of target materials derives from multi-disciplinary criteria such as target performance, fabricability, safety and environment, corrosion, and cost of recycle. Indirect-drive targets require high- $Z$ materials for the hohlraum. Gold and gadolinium are favorite target materials for laboratory experiments but cost considerations may preclude their use in power plants or at least requires cost effective recycle because a year's supply of gold and gadolinium is estimated at $520 \mathrm{M} \$$ and $40 \mathrm{M} \$$. Environmental and waste considerations alone require recycle of this material. Separation by volatility appears to be the most attractive (e.g., $\mathrm{Hg}$ and $\mathrm{Xe}$ ); centrifugation (e.g., $\mathrm{Pb}$ ) is acceptable with some problems (e.g., materials compatibility) and chemical separation is the least attractive (e.g. Gd and $\mathrm{Hf}$ ). Mercury, hafnium and xenon might be substituted with equal target performance and have advantages in removal and recycle due to their high volatility, except for hafnium. Alternatively, lead, tungsten and xenon might be used due to the ability to use centrifugation and gaseous separation. Hafnium or tantalum form fluorides, which will complicate materials compatibility, corrosion and require sufficient volatility of the fluoride for separation. Further complicating the coolant cleanup and processing is the formation of free fluorine due to nuclear transformation of lithium and beryllium in the flibe, which requires chemical control of the fluoride level to minimize corrosion. The study of the choice of target materials and the appropriate processing needs further study because we have not come up with choices which perform as well as gold and gadolinium and which have practical processes for recovery and recycle.
\end{abstract}


Table of contents

1. Introduction 2

2. Choice of high $\mathrm{Z}$ hohlraum material 3

3. Process rates 9

4. Processes for removing high-Z materials 11

$\begin{array}{ll}\text { 4.1 Distillation or volatility separation } & 11\end{array}$

4.2. Centrifugation separation 12

4.3 Reductive extraction/metal transfer 13

5. Impurity cleanup system 14

6. Removal of solid particulates $\quad 18$

7. Cost of processing $\quad 18$

8. Safety and environment considerations 21

9. Alternatives to flibe systems 21

10. Conclusions 22

11. Acknowledgments 23

12. References 23 


\section{Introduction}

This report is based on two memos (Moir, 1996 and Moir, 1997), which were part of an industrial ecology study of inertial fusion energy (IFE) at UC Berkeley, Department of Nuclear Engineering (Lowenthal et al., 1999), although some recent material has been included. The inventory of flibe coolant must be processed to keep impurities from building up. The sources of impurities are target debris, transmutation products (principally tritium and helium), corrosion products, pump cover gases, in-leakage of air and water, and other minor sources. A schematic of the molten salt processing system for HYLIFE-II is shown in Fig. 1. The point of this note is to discuss the processes and equipment required so as to determine the cost and resulting impurity levels. Another purpose is to aid target designers in helping decide which materials are acceptable.

Most of the flow is simply recirculated to the chamber to form the thick-liquid blanket. A fraction (to be determined) of the recirculating flow is diverted to a salt clean-up system. About $20 \%$ of the flow is directed to the heat exchangers, first passing through a vacuum disengager for tritium recovery. The flow rate of the coolant to the heat exchangers of the balance of plant (BoP) is 10 and $20 \mathrm{~m}^{3} / \mathrm{s}$ for 2500 and 5000 MWth which corresponds roughly to an electrical power output of 1000 and 2000 MWe (Moir et al., 1994 and House, 1994). The total volume of flibe coolant is approximately $1200 \mathrm{~m}^{3}$ and $2000 \mathrm{~m}^{3}$ for the two plant sizes.

\section{Choice of high $\mathrm{Z}$ hohlraum material}

Target design studies have evaluated the performance of a number of material combinations and compared them to the standard choice of gold and gadolinium 
in about equal amounts (Callahan-Miller and Tabak, 2000). The criteria for selecting hohlraum materials are many: target performance (which depends on

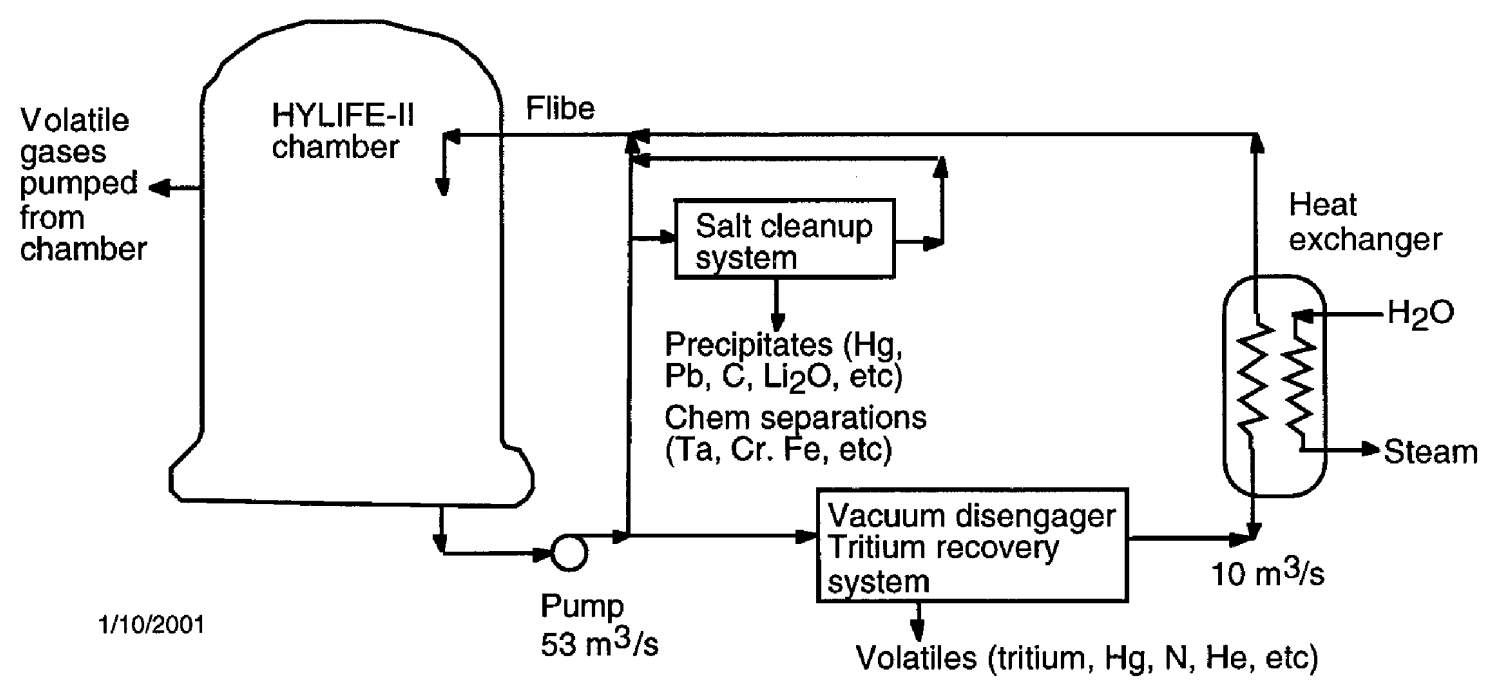

Fig. 1. Molten salt processing system for HYLIFE-II.

photon cross sections in the range of $\sim 50 \mathrm{eV}$ to $\sim 3 \mathrm{keV}$ ), chemical compatibility with steel ( $\mathrm{Fe}, \mathrm{Cr}$ and $\mathrm{Ni}$ ), separability from flibe, radio-toxicity, etc. The UC Berkeley industrial ecology study chose three candidates: $\mathrm{Hg}, \mathrm{Pb}$ and $\mathrm{Ta}$. To this list we could add more candidates, e.g., Gd, $\mathrm{Xe}, \mathrm{Hf}, \mathrm{Bi}, \mathrm{Rn}$. Photoelectric cross sections for some elements are given in Fig. 2. A mixture of two elements is used because the combination can fill holes in the opacity of a single element. As a result a mixture of two elements can re-emit more radiation back into the hohlraum interior than just one element. The wall absorption can be decreased as much as $28 \%$ for example with $50 \% \mathrm{Au}+50 \% \mathrm{Gd}$ compared to $100 \% \mathrm{Au}$ (Callahan-Miller and Tabak, 2000). The filler element might be lower in $\mathrm{Z}$ by $\sim 15$ and has a broad optimum around a 50-50 mixture but can be as low as 30-70 mixture (Larry Suter, 1996). The rare-earth elements (Lanthanides with atomic number between 58 and 71) appear to be the likely filler element. Table 1 gives results from the Callahan-Miller and Tabak, 2000 paper. The uranium and thorium cases are from Suter et al. (2000). It would appear a combination of several elements might be appropriate. 
A two week inventory of gold at $350 \$ / \mathrm{oz}$ would amount to $\$ 20 \mathrm{M}(520 \mathrm{M} \$$ for a year's supply). Au is not eliminated but cost is a negative factor. Radon ( Rn) might be good for the Au substitute due to its extra high $\mathrm{Z}$ and ease of recovery due to it being a gas, but dealing with the alpha radioactivity seems to preclude its use. Fissionable materials like Th and $U$ also seem to be precluded because of production of radioactivity but targets likely would perform better due to the

Table 1

Target performance of various wall materials

\begin{tabular}{|l|c|}
\hline Material & $\mathrm{E}_{\text {wall }} / \mathrm{E}_{\text {wall AuGd }}$ \\
\hline $\mathrm{Au} / \mathrm{Gd}(50: 50)$ & 1.00 \\
\hline $\mathrm{Au}$ & 1.25 \\
\hline $\mathrm{Pb}$ & 1.28 \\
\hline $\mathrm{Hg}$ & 1.26 \\
\hline $\mathrm{Ta}$ & 1.25 \\
\hline $\mathrm{W}$ & 1.25 \\
\hline $\mathrm{Pb} / \mathrm{Ta}(50: 50)$ & 1.08 \\
\hline $\mathrm{Pb} / \mathrm{Ta}(70: 30)$ & 1.06 \\
\hline $\mathrm{Hg} / \mathrm{Xe}(50: 50)$ & 1.18 \\
\hline $\mathrm{Pb} / \mathrm{Ta} / \mathrm{Cs}(50: 20: 30)$ & 1.01 \\
\hline $\mathrm{Pb} / \mathrm{Ta} / \mathrm{Cs}(45: 20: 35)$ & 1.01 \\
\hline $\mathrm{Hg} / \mathrm{Ta} / \mathrm{Cs}(45: 20: 35)$ & 1.03 \\
\hline $\mathrm{Hg} / \mathrm{W} / \mathrm{Cs}(45: 20: 35)$ & 1.04 \\
\hline $\mathrm{Pb} / \mathrm{Hf}(70: 30)$ & 1.04 \\
\hline $\mathrm{Pb} / \mathrm{Hf} / \mathrm{Xe}(45: 20: 35)$ & 1.00 \\
\hline $\mathrm{Th} / \mathrm{Bi} / \mathrm{Ta} / \mathrm{Sm} / \mathrm{Cs}$ & 0.82 \\
\hline $\mathrm{U} / \mathrm{Pb} / \mathrm{Ta} / \mathrm{Dy} / \mathrm{Nd}$ & 0.76 \\
\hline
\end{tabular}

higher albedo from these higher $\mathrm{Z}$ materials. With thorium as the high $\mathrm{Z}$ material ( $30 \mu \mathrm{m}$ layer at $10 \mathrm{~mm}$ radius) there would be about $1350 \mathrm{~g} / \mathrm{y}(43.5$ $\mu \mathrm{g} / \mathrm{s})$ production rate of ${ }^{231} \mathrm{~Pa}(32,000 \mathrm{y}$, alpha emitter, from the $\mathrm{n}, 2 \mathrm{n}$ reaction followed by beta decay), $450 \mathrm{~g} / \mathrm{y}(14 \mu \mathrm{g} / \mathrm{s}){ }^{230} \mathrm{Th}(75,000 \mathrm{y}$, alpha emitter, from the $n, 3 \mathrm{n}$ reaction), and $450 \mathrm{~g} / \mathrm{y}$ of fission products for $1 \mathrm{GWe}$. The production rate of materials like these would be about the same but with about four times as many fission products with uranium. The actinide elements can be removed by reacting with beryllium. The hazard of these radioactive elements needs to be estimated and compared to the activation of other candidate materials such as $\mathrm{Hg}$ and $\mathrm{Pb}$ before they are dismissed out of hand because they might improve target performance. A survey of possible candidate high- $Z$ target elements plus 
lower $\mathrm{Z}$ elements down to $\mathrm{Z}=54$ to fill the opacity hole are listed in Table 2. Once we know the criteria for selection and enough performance data we can choose a set of materials.

Preliminary screening (guessing) is used to eliminate many of the elements in Table 2 resulting in a reduced set in Table 3. Since this early work was done a computer code was used (Callahan-Miller and Tabak, 2000) to study albedo to help select the elements to use. This work should be extended.

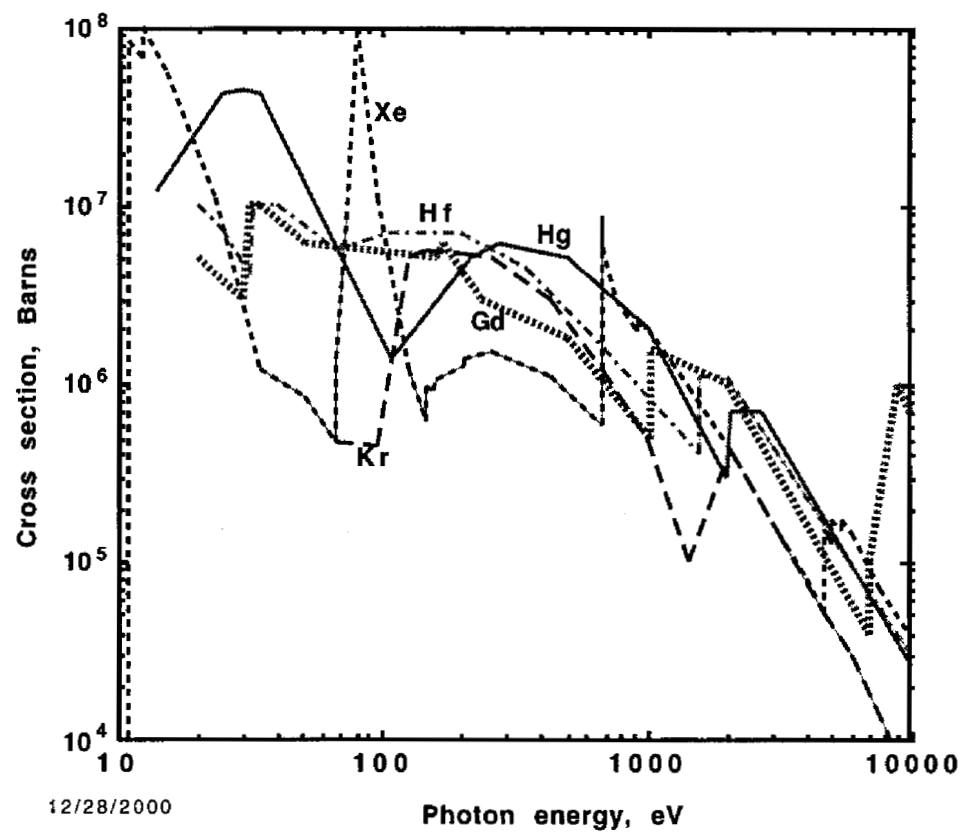

Fig. 2. Photoelectric cross-sections for some candidate target hohlraum wall materials.

Its been estimated that the wall absorption might increase by $28 \%$ for $\mathrm{Pb}$ compared to a $50 \% \mathrm{Gd}$ and $50 \%$ Au mix giving a $13.5 \%$ decrease in target gain (Callahan-Miller and Tabak, 2000). A calculation shows a 13.5\% decrease in gain from a gain of 60 at $5.5 \mathrm{MJ}$ driver energy would result in an approximate $5 \%$ increase in cost of electricity for a $1 \mathrm{GWe}$ plant. This is equivalent to a $130 \mathrm{M} \$$ capital cost increase (65 $\mathrm{M} \$$ direct). We need to see if the added cost of the process equipment needed to process the second material is worth the expense. A legitimate question is, "how much effort at this stage of IFE development should we put into optimizing the target materials and studying the 
processing?" 
Table 2

Candidate elements for hohlraum walls

\begin{tabular}{|c|c|c|c|}
\hline $\bar{Z}$ & Element & Comments & separation methods \\
\hline 96 & Gmt & $\begin{array}{l}\text { makes fission products, unstable, } \\
\text { alpha emitter }\end{array}$ & React with beryllium \\
\hline 95 & Am & " & $"$ \\
\hline 94 & $\mathbf{P t z}$ & $\pi$ & $\pi$ \\
\hline 93 & $\mathbf{N p}_{\mathbf{p}}$ & $"$ & $"$ \\
\hline 92 & $\bar{U}$ & $\pi$ & $"$ \\
\hline 91 & $\mathbf{P a}$ & $"$ & $"$ \\
\hline 90 & $\mathbf{T h}$ & " & $\pi$ \\
\hline 89 & $\overline{\text { Afe }}$ & unstable, alpha emitter & 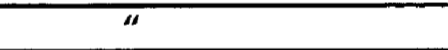 \\
\hline 88 & Rat & alpha emitter & $\pi$ \\
\hline 87 & $\overline{F_{x}}$ & unstable & $"$ \\
\hline 86 & $\overline{\operatorname{Rn}}$ & $\begin{array}{l}\text { alpha emitter; short half-life } \\
\text { too costly } \sim \$ 300 / \text { target }\end{array}$ & volatility \\
\hline 85 & $\overline{\text { At }}$ & $" 1$ & \\
\hline 84 & Po & unstable, alpha emitter & \\
\hline 83 & $\mathbf{B i}$ & & centrifuge \\
\hline$\overline{82}$ & $\overline{\mathbf{P b}}$ & & $" 1$ \\
\hline 81 & T1 & & $"$ \\
\hline 80 & $\mathbf{H g}$ & & volatility, centrifuge \\
\hline 79 & Aut & too costly? & centrifuge \\
\hline 78 & Pt & too costly? & “ \\
\hline 77 & Ir & too costly? & " \\
\hline 76 & $\theta s$ & too costly? & 4 \\
\hline 75 & $\operatorname{Re}$ & & " \\
\hline 74 & $\mathbf{W}$ & & " \\
\hline 73 & $\mathbf{T a}$ & & $\begin{array}{l}\mathrm{TaF}_{5} \text {, volatility, } \\
\text { electrochemical }\end{array}$ \\
\hline 72 & Hf & & $\mathrm{HfF}_{4}$, electrochemical \\
\hline 71 & $\mathbf{L u}$ & & $\begin{array}{l}\text { reductive extraction } / \text { metal } \\
\text { transfer }=\mathrm{Bi} \text { extraction }\end{array}$ \\
\hline 70 & $\mathbf{Y b}$ & & $\mathrm{YbF}_{3}, \quad$ Bi extraction \\
\hline 69 & $\operatorname{Tm}$ & & $\mathrm{TmF}_{3}, \quad$ Bi extraction \\
\hline 68 & Er & & ErF $_{3} \quad$ Bi extraction \\
\hline 67 & Ho & & $\mathrm{HoF}_{3} \quad \mathrm{Bi}$ extraction \\
\hline 66 & Dy & & DyF $_{3} \quad$ Bi extraction \\
\hline 65 & $\mathrm{~Tb}$ & & $\mathrm{TbF}_{3,}$ Bi extraction \\
\hline 64 & $\mathbf{G d}$ & & $\mathrm{GdF}_{3,} \quad$ Bi extraction \\
\hline 63 & $\mathbf{E t}$ & too costly & EuF $_{3}, \quad$ Bi extraction \\
\hline 62 & Sm & & $\mathrm{SmF}_{3}, \quad$ Bi extraction \\
\hline 61 & Pmt & unstable & $\mathrm{PmF}_{3}, \quad$ Bi extraction \\
\hline 60 & $\mathrm{Nd}$ & & $\mathrm{NdF}_{3}, \quad \mathrm{Bi}$ extraction \\
\hline 59 & Pr & & $\mathrm{PrF}_{3} \mathrm{PrF}_{4}, \mathrm{Bi}$ extraction \\
\hline 58 & $\mathrm{Ce}$ & & Bi extraction \\
\hline 57 & $\mathbf{L a}$ & & $\mathrm{LaF}_{3}, \quad$ Bi extraction \\
\hline
\end{tabular}




\begin{tabular}{|l|l|l|l|}
\hline 56 & Ba & & $\begin{array}{l}\text { not volatility, not centrifuge, } \\
\mathrm{BaF}_{2,} \text {,chemically similar } \\
\text { toLiF }\end{array}$ \\
\hline 55 & $\mathrm{Cs}$ & & $\mathrm{CsF}_{2} \quad$ volatility, \\
\hline 54 & $\mathrm{Xe}$ & & \multicolumn{1}{|c|}{ volatility } \\
\hline
\end{tabular}

Table 3

Reduced set of candidate elements for hohlraum walls

\begin{tabular}{|c|c|c|c|}
\hline $\bar{Z}$ & Element & Comments & separation methods \\
\hline 83 & $\mathbf{B i}$ & & centrifuge \\
\hline 82 & $\mathbf{P b}$ & & $"$ \\
\hline 81 & T1 & & " \\
\hline 80 & $\mathrm{Hg}$ & low cost separation- - & volatility, centrifuge \\
\hline 75 & $\operatorname{Re}$ & & \\
\hline 74 & $\mathbf{W}$ & & " \\
\hline 73 & Ta & & $\mathrm{TaF}_{5}$, volatility, electrochemical \\
\hline 72 & $\overline{\mathbf{H f}}$ & & $\mathrm{HfF}_{4}$ electrochemical \\
\hline$\overline{71}$ & $\mathbf{L u}$ & & Bi extraction \\
\hline 70 & $\overline{Y b}$ & & Bi extraction \\
\hline 69 & $\operatorname{Tm}$ & & $\mathrm{TmF}_{3}, \quad \overline{B i}$ extraction \\
\hline 68 & $\overline{E r}$ & & Bi extraction \\
\hline 67 & Ho & & Bi extraction \\
\hline 66 & $\overline{D y}$ & & Bi extraction \\
\hline 65 & $\overrightarrow{\mathrm{Tb}}$ & & Bi extraction \\
\hline 64 & $\mathbf{G d}$ & & Bi extraction \\
\hline 62 & Sm & & Bi extraction \\
\hline 60 & Nd & & Bi extraction \\
\hline 59 & $\overline{\mathbf{P r}}$ & & $\operatorname{PrF}_{3}, \operatorname{PrF}_{4}$, Bi extraction \\
\hline 58 & $\mathrm{Ce}$ & & $\mathrm{CeF}_{3,} \quad$ Bi extraction \\
\hline 57 & $\overline{\mathbf{L a}}$ & & Bi extraction \\
\hline 55 & Cs & & volatility, electrochemical, CsF \\
\hline 54 & $\mathbf{X e}$ & low cost separation-----> & volatility \\
\hline
\end{tabular}

The lanthanides are not very volatile and form fairly stable fluorides. Recent advances in halide volatility separation of rare-earth elements need to be studied for applicability to the IFE case (Fray, 2000). The separation technology might be to contact the salt with bismuth and extract in a continuous flow centrifuge/contactor. These tend to be sized at $\sim 1 \mathrm{l} / \mathrm{min}$ in present versions. They would have to be scaled up by a large factor making for a worrisome cost. The volatility and centrifuge processes look more attractive. Table 2 should be extended down to lower $\mathrm{Z}$ elements. 


\section{Process rates}

Table 4 gives some target materials from several old sources. Some materials, such as ablators, might have to be added if they can not be made of constituents of flibe or those given in the table. We consider for target debris $0.25 \mathrm{~g}$ of $\mathrm{Pb}, \mathrm{Hg}$ or Ta as examples (a little inconsistent with Table 4, which uses $0.22 \mathrm{~g}$ ). The processes we have in mind are chemical, electro-chemical, and physical. $\mathrm{Hg}$ and $\mathrm{Pb}$ do not form fluorides in flibe and are insoluble. They are heavy and centrifugation can separate them. $\mathrm{Hg}$ is volatile and can be separated by evaporation (distillation). Ta reacts with flibe forming $\mathrm{TaF}_{5}$, which is volatile. However, to make the reaction go, the fluoride content must be high making for excessive corrosion of the steel wall material. In the metallic form, the melting point of Ta is high. The form Ta would take is a powder precipitate, a difficult form to deal with, although centrifugation needs to be considered to see if filtration of the precipitate could be workable. For these reasons (corrosion and high melting point) $\mathrm{Ta}$ is not recommended for use in targets.

We consider various processing rates shown in Table 5 by processes to be discussed later. A reasonably small process rate of 1 liter/s will result in $1740 \mathrm{~kg}$ of radioactive mercury or other high $\mathrm{Z}$ material build up in the flibe to $700 \mathrm{ppm}$. The mercury recovered would then be reused in new targets. The issues involved with using radioactive mercury and other elements need study. 
Table 4

Input rates from targets and in-leakage

\begin{tabular}{|l|l|l|}
\hline & $\begin{array}{l}\text { In flibe } \\
\text { removal by separation }\end{array}$ & $\begin{array}{l}\text { From unburned targets } \\
\text { removal by pumping }\end{array}$ \\
\hline Tritium $^{\mathrm{a}}$ & $\begin{array}{l}0.75 \mathrm{mg} / \mathrm{shot} \\
4.35 \mathrm{mg} / \mathrm{s}\end{array}$ & $\begin{array}{l}1.2 \mathrm{mg} / \mathrm{shot} \\
7.0 \mathrm{mg} / \mathrm{s}\end{array}$ \\
\hline helium $^{\mathrm{a}}$ & $\begin{array}{l}0.99 \mathrm{mg} / \mathrm{shot} \\
5.74 \mathrm{mg} / \mathrm{s}\end{array}$ & $\begin{array}{l}0.85 \mathrm{mg} / \mathrm{shot} \\
4.9 \mathrm{mg} / \mathrm{s}\end{array}$ \\
\hline deuterium $^{\mathrm{a}}$ & -- & $\begin{array}{l}0.79 \mathrm{mg} / \mathrm{shot} \\
4.58 \mathrm{mg} / \mathrm{s}\end{array}$ \\
\hline high Z material $^{\mathrm{a}}$ & $220 \mathrm{mg} / \mathrm{shot}$ & \\
\hline $\mathrm{H}^{\mathrm{b}}$ membranes & $\begin{array}{l}1.28 \mathrm{~g} / \mathrm{s} \\
0.29 \mathrm{mg} / \mathrm{shot}\end{array}$ & \\
\hline $\mathrm{O}^{\mathrm{b}}$ “ & $0.04 \mathrm{mg} / \mathrm{shot}$ & \\
\hline $\mathrm{C}^{\mathrm{b}}$ " & $0.23 \mathrm{mg} / \mathrm{s}$ & \\
\hline $\mathrm{Cr}^{\mathrm{c}}$ & $0.075 \mathrm{mg} / \mathrm{shot}$ & \\
\hline $\mathrm{Fe}^{\mathrm{c}}$ & $0.5 \mathrm{mg} / \mathrm{s}$ & \\
\hline $\mathrm{Ni}^{\mathrm{c}}$ & $1.8 \mathrm{mg} / \mathrm{s}$ & \\
\hline $\mathrm{N}^{\mathrm{d}}$ & $0.3 \mathrm{mg} / \mathrm{s}$ & \\
\hline $\mathrm{O}^{\mathrm{d}}$ & $0.12 \mathrm{mg}$ & \\
\hline $\mathrm{Ne}^{\mathrm{d}}$ & $0.65 \mathrm{mg}$ & \\
\hline $\mathrm{N}^{\mathrm{e}}$ & $0.065 \mathrm{mg}$ & \\
\hline $\mathrm{O}^{\mathrm{e}}$ & $?$ & \\
\hline $\mathrm{H}_{2} \mathrm{O}^{\mathrm{f}}$ & $?$ & \\
\hline
\end{tabular}

a-(Table II of Moir et al. 1994).

b-From membranes of targets assuming 6 membranes, $16 \mathrm{~mm}$ dia., $0.1 \mu \mathrm{m}$ thick

Mylar $\left(\mathrm{C}_{10} \mathrm{H}_{8} \mathrm{O}_{4}\right)$ membranes per target.

c-Corrosion products (see text).

d-transmutation products from fluorine, Latkowski private comm. 1/2001.

e-air leaks

f-water leaks 
Table 5

Process rates

\begin{tabular}{|l|l|l|l|}
\hline $\begin{array}{l}\text { Process rate } \\
\text { liters } / \mathrm{s}\end{array}$ & $\begin{array}{l}\text { Time to process } \\
\text { total inventory }\end{array}$ & \multicolumn{2}{|l|}{$\begin{array}{l}\text { Inventory of high Z } \\
\text { material } \\
\mathrm{kg} \quad \text { wppm in flibe }\end{array}$} \\
\hline 10,000 & $120 \mathrm{~s}(2 \mathrm{~min})$ & 0.17 & 0.07 \\
\hline 100 & $1.2 \times 10^{4} \mathrm{~s}(3.3 \mathrm{hrs})$ & 17.4 & 7 \\
\hline 1 & $1.2 \times 10^{6} \mathrm{~s}(14$ days $)$ & 1740 & 700 \\
\hline
\end{tabular}

\section{Processes for removing high- $\mathrm{Z}$ materials}

Three processes in order of decreasing simplicity and increasing cost will be discussed: distillation or volatility separation, centrifugation separation, and reductive extraction/metal transfer.

\subsection{Distillation or volatility separation}

The unusually high process rate of $10,000 \mathrm{l} / \mathrm{s}$ is the entire flow of flibe to the steam generators after passing though the vacuum-disengager, tritium removal system (Dolan and Longhurst, 1992). Tritium is removed by a volatility process whereby the liquid is sprayed in two, series flow "drop towers". The tritium diffuses out of small droplets and is pumped away. Volatile materials like $\mathrm{Hg}$ (and Xe or CsF) could also be separated from the liquid in this equipment. By installing cool plates, the $\mathrm{Hg}$ can be made to condense as a liquid and flow to a collection point as shown in Fig. 3. 


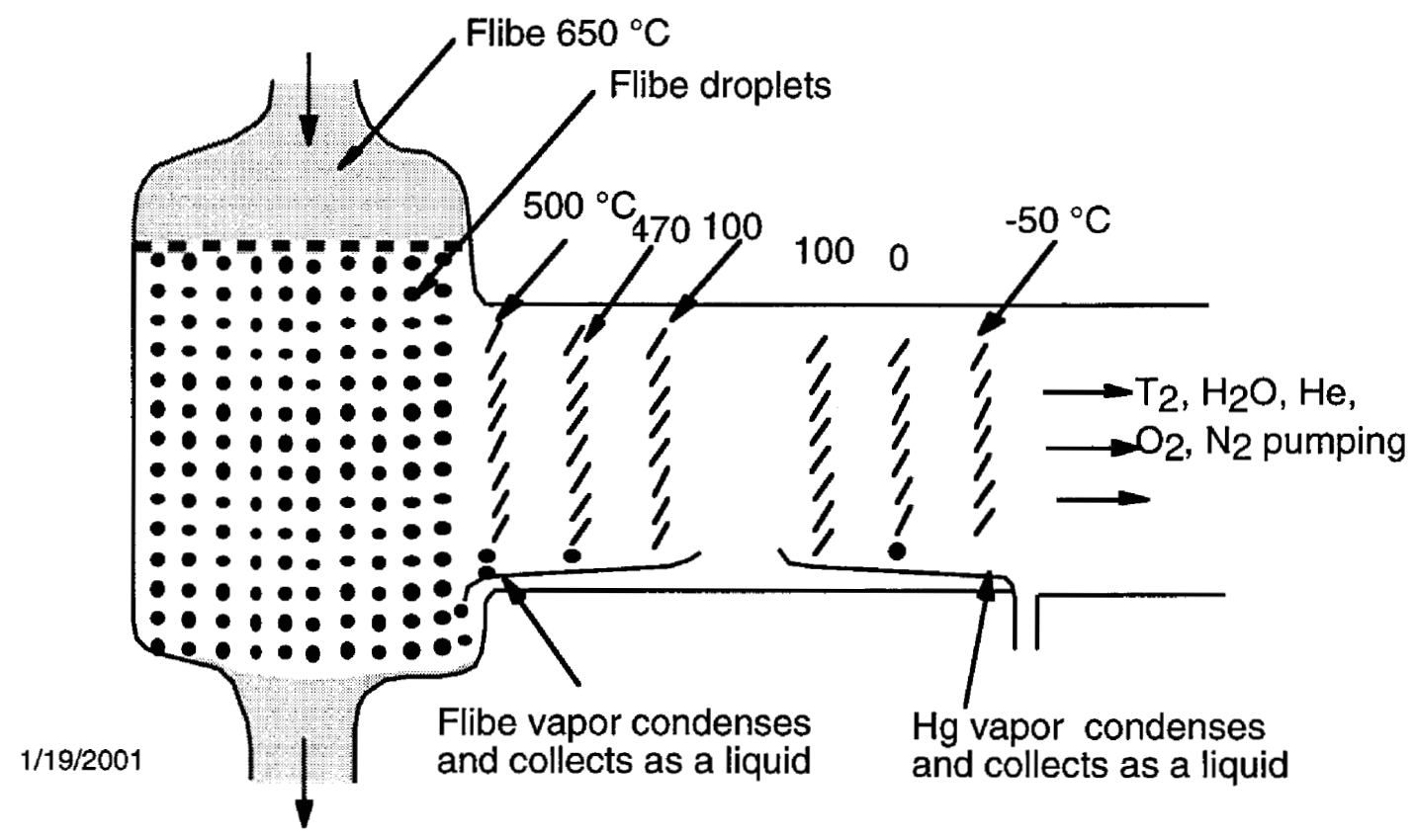

Fig. 3. Vacuum disengager modified to remove mercury vapor and other volatile materials from flibe.

The flibe itself has a relatively high vapor pressure and would be condensed first on a set of higher temperature plates held just above the freezing point of flibe $\left(460^{\circ} \mathrm{C}\right) .\left[\mathrm{TaF}_{5}\right.$ can also be separated by this volatility method. However, the flibe fluoride content would be so high that $\mathrm{Cr}$ and Fe would be fluoridized from steel as well. So the salt will be kept reduced and Ta would be in metallic form. As mentioned before Ta is not recommended.] The cost should be modest because much of the separation equipment is already in place for separating tritium. To be quantitative the evaporation rates need to be estimated. For $\mathrm{Hg}$ about $10 \mathrm{~m}^{2}$ of condensing plates appears adequate. A small fraction of the $10,000 \mathrm{l} / \mathrm{s}$ flow rate would be adequate, for example, $1 \mathrm{l} / \mathrm{s}$ would probably do for $\mathrm{Pb}$ as will be discussed below.

\subsection{Centrifugation separation}

Another process is centrifugation as shown in Fig. 4. 


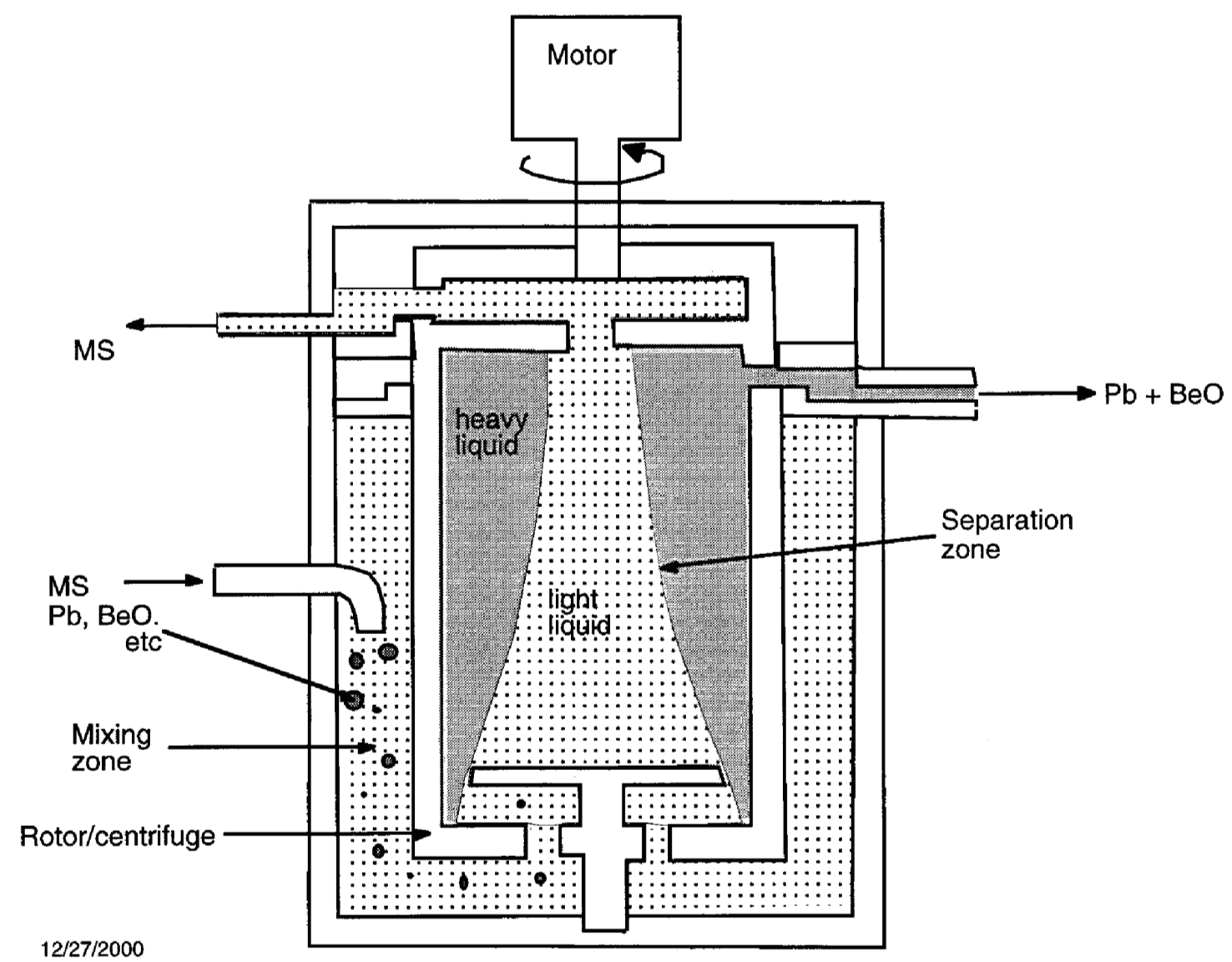

Fig. 4. Schematic illustration of a centrifugal separator design from a working ANL cadmium-chloride salt contactor (Chow et al, 1993).

A reasonable sized continuous flow centrifuge of $1 \mathrm{l} / \mathrm{s}$ would be adequate to process the $1240 \mathrm{~m}^{3}$ inventories in 13.9 days $(1,200,000 \mathrm{~s})$. For the $2 \mathrm{GWe}$ case, 1.6 such units would be needed to process the $2000 \mathrm{~m}^{3}$ inventory in the same time. At a pulse rate of $5.8 \mathrm{~Hz}$ and $0.25 \mathrm{~g} /$ target the inventory would be $1,740 \mathrm{~kg}$ of heavy, high- $Z$ target material in the flibe. This would be about 700 wppm for the $1 \mathrm{GWe}$ case. The first stage of centrifugation would raise the concentration to the point where a small centrifuge could reduce the high- $Z$ material to a pure metal stream.

\subsection{Reductive extraction/metal transfer}

The lanthanides form stable fluorides that are soluble in flibe and have fairly low vapor pressure. Since the vapor pressure is low, volatility does not work well 
and because of solubility, centrifugation does not work. The next separation process to consider is called reductive extraction followed by metal transfer. This is a standard process in the salt pyroprocessing field for nuclear fuels. The salt is contacted in a continuous counter flow system with bismuth. The lanthanide fluorides preferentially transfer into the bismuth, which is heavy and can be separated by centrifugation. The flibe is of low solubility in Bi. The Bi containing the lanthanide fluoride is contacted with $\mathrm{LiCl}$ to transfer the lanthanide fluoride into the $\mathrm{LiCl}$. The $\mathrm{LiCl}$ is contacted with $\mathrm{Bi}$ containing a small amount of $\mathrm{Li}$. The lithium reduces the lanthanide fluoride, which can then be separated out as lanthanide elements. The process rate in this reductive extraction was $0.8 \mathrm{GPM}$ $(0.055 \mathrm{l} / \mathrm{s})$ in the example worked out in (Haubenreich and Briggs, 1972). The process is shown in Fig. 5. A step would have to be added to remove the lanthanide element from the $\mathrm{Bi}-\mathrm{Li}$ stream such as centrifugation assuming the solubility is low.

\section{Impurity cleanup system (see Shaffer, 1971)}

A clean up system to remove impurities will be needed in order to keep the flibe clean. These impurities are $\mathrm{O}, \mathrm{N}, \mathrm{C}, \mathrm{H}_{2} \mathrm{O}$, corrosion products $(\mathrm{Cr}, \mathrm{Fe}, \mathrm{Ni})$, and inert gases as well as target debris. The $\mathrm{Ne}, \mathrm{O}$, and $\mathrm{N}$ transmutation products from fluorine are already included in the impurities from other sources, except $\mathrm{Ne}$ which being a noble gas presents no problems and can easily be separated. $\mathrm{N}, \mathrm{H}$ and inert gases should be removed along with the volatile high- $\mathrm{Z}$ elements within the tritium removal system. $\mathrm{Cr}, \mathrm{Fe}$, and $\mathrm{Ni}$ can be removed by reacting with beryllium contactors. We have an estimate of $2 \mu \mathrm{m} / \mathrm{y}$ as the dissolution rate of steel into the flibe based on some flow loop experiments (Keiser, DeVan and Lawrence, 1979). Experiments with high nickel alloys show nil dissolution rate. It could be that the $\mathrm{Cr}$ and Fe near the austenitic steel surface dissolve leaving an enriched Ni coating and greatly diminished further dissolution. 


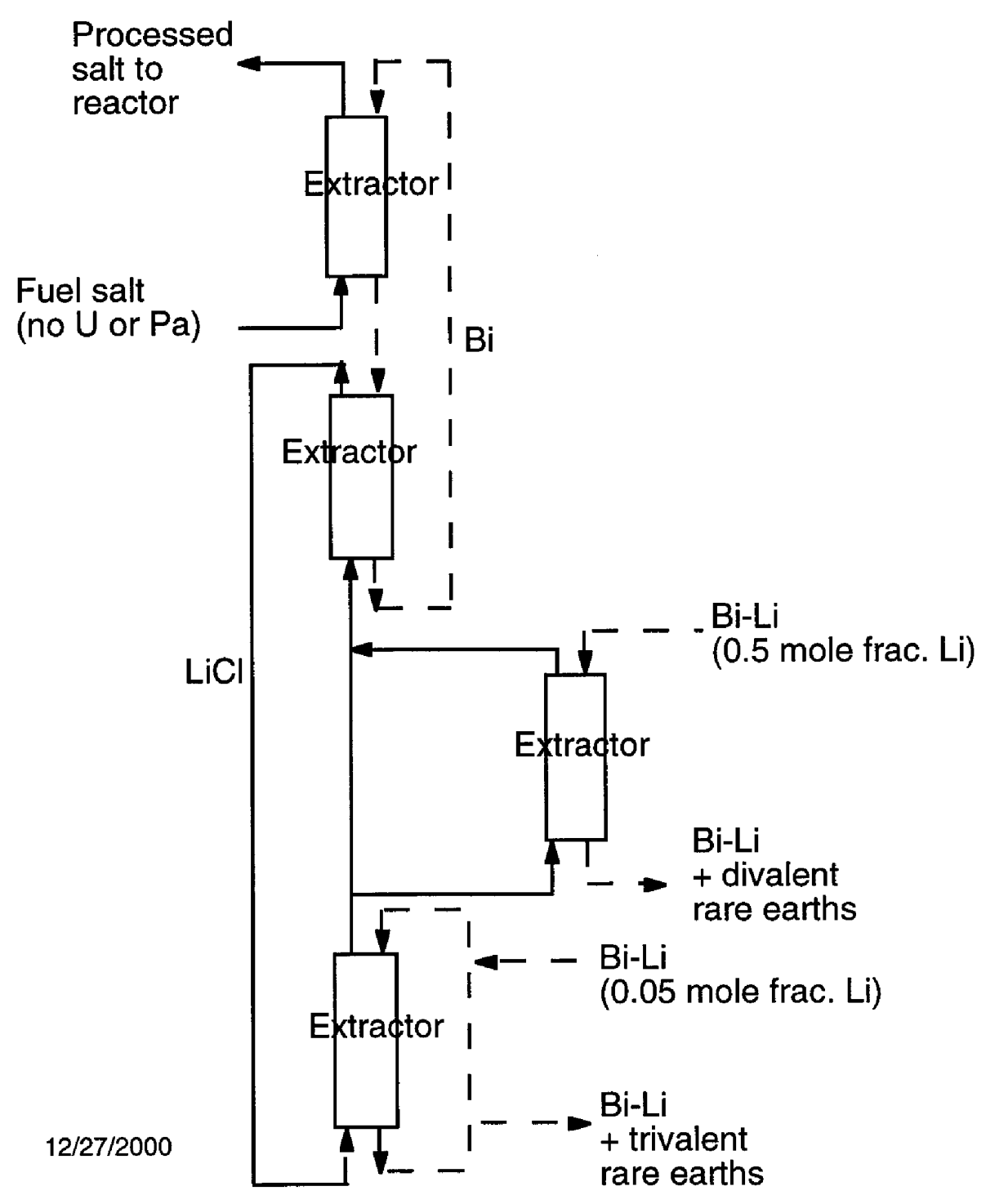

Fig. 5. Metal transfer process for removal of rare earths from single-fluid MSBR fuel salt (Fig. 11.5 from Haubenreich and Briggs, 1972).

This $2 \mu \mathrm{m} / \mathrm{y}$ will permit an estimate of the size of the removal system for the beryllium contactor system. The chemistry control of flibe due to production of free fluorine will increase this removal rate as discussed later. The area of wall exposed to the flibe is estimated at $5000 \mathrm{~m}^{2}\left(2500 \mathrm{MW}\right.$ th at $1 \mathrm{MW} / \mathrm{m}^{2}$ in the heat exchanges gives $2500 \mathrm{~m}^{2}$. The $1240 \mathrm{~m}^{3}$ of flibe if contained in a $1 \mathrm{~m}$ radius pipe ( 1 $m$ dia probably should have been used for the example) on average would result in another $2500 \mathrm{~m}^{2}$ giving a total of approximately $5000 \mathrm{~m}^{2}$. The dissolution rates 
of structure are obtained as follows: $5000 \mathrm{~m}^{2} \times 2 \mu \mathrm{m} / \mathrm{y} \times 8000 \mathrm{~kg} / \mathrm{m}^{3}=80 \mathrm{~kg} / \mathrm{y}$ $(19 \% \mathrm{Cr}, 70 \% \mathrm{Fe}, 10 \% \mathrm{Ni}$, which works out to $2.5 \mathrm{mg} / \mathrm{s}$ or $0.5 \mathrm{mg} / \mathrm{s} \mathrm{Cr}, 1.8 \mathrm{mg} / \mathrm{s}$ $\mathrm{Fe}$ and $0.3 \mathrm{mg} / \mathrm{s} \mathrm{Ni}$ ). The entries in Table 4 for steel constituents use these estimates.

$\mathrm{O}_{2}$ from air leaks and $\mathrm{H}_{2} \mathrm{O}$ from steam generator leaks will chemically react with flibe:

$$
\begin{array}{lll}
1 / 2 \mathrm{O}_{2}+2 \mathrm{LiF}----->\mathrm{Li}_{2} \mathrm{O}+\mathrm{F}_{2} & +17,300 \mathrm{Cal} & \text { endothermic } \\
1 / 2 \mathrm{O}_{2}+\mathrm{BeF}_{2}---->\mathrm{BeO}+\mathrm{F}_{2} & +64,600 \mathrm{Cal} & \text { endothermic } \\
\mathrm{H}_{2} \mathrm{O}+2 \mathrm{LiF}----->\mathrm{Li}_{2} \mathrm{O}+2 \mathrm{HF}+44,350 \mathrm{Cal} & \text { endothermic } \\
\mathrm{H}_{2} \mathrm{O}+\mathrm{BeF}_{2}----->\mathrm{BeO}+2 \mathrm{HF} & +2,090 \mathrm{Cal} & \text { mildly endothermic } \\
\mathrm{Li}_{2} \mathrm{O}+\mathrm{BeF}_{2}---->\mathrm{BeO}+2 \mathrm{LiF} & -42,260 \mathrm{Cal} & \text { exothermic }
\end{array}
$$

The first three equations above show that the reaction products on the right should be in very low concentrations. The $\mathrm{BeO}$ reaction product in equation 4 should be in a small concentration and depends on the concentration of $\mathrm{H}_{2} \mathrm{O}$. $\mathrm{BeO}$ is the more stable oxide in flibe compared to $\mathrm{Li}_{2} \mathrm{O}$ as shown in equation 5. The moisture content in flibe is removed in the following reaction:

$\mathrm{BeO}+2 \mathrm{HF}+\mathrm{H}_{2}---->\mathrm{H}_{2} \mathrm{O}+\mathrm{BeF}_{2}+\mathrm{H}_{2}$

This moisture-removal process (scrubbing) is done off-line with $10 \% \mathrm{HF}+90 \%$ $\mathrm{H}_{2}$ (hydro-fluorination). The $\mathrm{H}_{2} \mathrm{O}$ is volatile and removed as a vapor in a getter bed. The added $\mathrm{H}_{2}$ serves to prevent corrosion of Ni containers. Ni can resist corrosion by $\mathrm{HF}+90 \% \mathrm{H}_{2}$, but $\mathrm{Cr}$ and $\mathrm{Fe}$ cannot, so this scrubbing process needs to be done in a off-line nickel system. 304 or 316 SS may be acceptable because the $\mathrm{Cr}$ and Fe quickly becomes depleted near the surface and "looks" 
like a nickel container for practical purposes (Keiser, DeVan and Lawrence, 1979). In order to keep the oxygen content of the salt low we will need a continuous hydro-fluorination step. This will have to be sized and costed. The size of the hydro-fluorination system and allowed buildup concentration of $\mathrm{HF}$ and $\mathrm{BeO}$ will result in calculating a maximum size water leak rate for which we would continue operating the system until a shut down period to plug the leak. It may very well be possible to avoid the clean up process shown in Eq. 6 by simply removing $\mathrm{H}_{2} \mathrm{O}$ in the vacuum disengager because the reactions are endothermic but where would the HF come from? Adding HF would make the system too corrosive.

One idea behind chemistry control when using flibe in fusion systems is to continually remove $\mathrm{HF}$ by reaction with beryllium. If beryllium is soluble in flibe even at extremely small concentrations, then the HF can be easily removed by the reaction

$2 \mathrm{HF}+\mathrm{Be}---->\mathrm{BeF}_{2}+\mathrm{H}_{2}$

Even if beryllium is not soluble in flibe it can be finely dispersed by adding beryllium and/or lithium to targets, which upon exploding become vaporized and dispersed. Lithium fluoride is more stable than beryllium fluoride so adding lithium is a way to provide beryllium as can be seen from the following equation $2 \mathrm{Li}+\mathrm{BeF}_{2}--->2 \mathrm{LiF}+\mathrm{Be}$

Experiments are needed to determine the solubility of beryllium in flibe and if it is too low to determine the effectiveness of dispersing beryllium in flibe.

The steam generators, which are double-walled, could have an inert gas between the water tubes and the flibe tubes so that in-leakage to the flibe would be primarily inert gas with the little water vapor that remains in the inert gas from water tube leaks. The present design calls for double-wall steam generators so that cracks will not propagate all the way through but has no purge system for the space between the walls. 


\section{Removal of solid particulates}

The removal of nondissolved material such as $\mathrm{C}$ and $\mathrm{BeO}$ (slag, precipitates) will require special attention. The amount of this material should be minimized as clogging of the spray system can be a problem where we have many small holes of $0.2 \mathrm{~mm}$ dia in the vacuum disengager tritium removal system. This spray system is part of the tritium removal system. In essence, this spray system can be considered a filter needing periodical servicing. Alternatively, a filter system can be installed on a slip stream with the filter size smaller than the $0.2-\mathrm{mm}$ diameter of the spray system. The centrifuge will or could be used to separate particulates that are heavier (precipitates) or lighter (flotsam) than flibe ( $\rho=2050$ $\mathrm{kg} / \mathrm{m}^{3}$ ). The specific gravity of $\mathrm{C}$ and $\mathrm{Li}_{2} \mathrm{O}$ are close to that of flibe but $\mathrm{BeO}$ is about 3.0.

\section{Cost of processing and cost of materials}

The tritium processing system using vacuum disengagers has been estimated to cost 60 and $100 \mathrm{M} \$(1995 \$)$ direct for 1 and 2 GWe, respectively. There have been several reports written on this system, for example (Longhurst and Dolan, 1993). Many of the volatility separation processes discussed later can use much of this equipment so the added cost should be modest. The cost of the flibe cleanup system currently being used in the systems code is 19 and $37 \mathrm{M} \$$ direct for 1 and $2 \mathrm{GWe}$, respectively, with little or no basis nor any studies carried out or reports written.

A cost estimate first requires a process description with flow sheets and specifications. Lacking these we attempt to put bounds on the cost. We also assume the process equipment will fit into buildings and facilities with remote equipment that is already present and covered in the tritium process systems, the salt cleanup system and the target fabrication system. We assume the form of the material that is useable is liquid $\mathrm{Hg}$, solid or liquid $\mathrm{Pb}$, gaseous $\mathrm{Xe}$ or solid lanthanide in elemental form. 
The volatility system should cost a fraction of the vacuum disengager tritium system of $\$ 60 \mathrm{M}$. Lets assume $\$ 10 \mathrm{M}$ as an order of magnitude. The cost is likely to scale as a power of process rate, PR. Perhaps $C \sim P R^{0.6}$. The nominal process rate is $100 \mathrm{l} / \mathrm{s}$. The centrifuge system is likely to cost about the same at a process rate of $1 \mathrm{l} / \mathrm{s}$. The reductive extraction might cost more than twice this much at a process rate of $0.1 \mathrm{l} / \mathrm{s}$. The low process rates imply a high inventory. These rough order of magnitude estimates are summarized in Table 6 . The volatility process is so simple it might cost less than the $10 \mathrm{M} \$$ estimate, the centrifuge process seems about right and the reductive extraction has a number of extra steps and might be more than the $20 \mathrm{M} \$$ estimate. The sense of these order of magnitude estimates is that the $10 \mathrm{M} \$$ might be 3 to $30 \mathrm{M} \$$. More refinement is needed and much caution to the reader is recommended.

Table 6

\section{Process cost estimates}

(order of magnitude)

\begin{tabular}{|l|l|l|l|l|}
\hline Process & Cost est. & $\begin{array}{l}\text { Process rate, } \\
\text { PR }\end{array}$ & Cost scaling & $\begin{array}{l}\text { Inventory/ } \\
\text { concentration } \\
/ \text { holdup time }\end{array}$ \\
\hline Volatility, Hg & $\$ 10^{7}$ & $100 \mathrm{l} / \mathrm{s}$ & $(\mathrm{PR})^{0.6}$ & $\begin{array}{l}0.17 \mathrm{~kg} / 7 \\
\mathrm{wppm} / 3.3 \mathrm{hr}\end{array}$ \\
\hline $\begin{array}{l}\text { Centrifugation, } \\
\text { Pb }\end{array}$ & $\$ 10^{7}$ & $1 l / \mathrm{s}$ & $(\mathrm{PR})^{0.6}$ & $\begin{array}{l}1740 \mathrm{~kg} / 700 \\
\mathrm{wppm} / 13.9 \mathrm{~d}\end{array}$ \\
\hline $\begin{array}{l}\text { Reductive } \\
\text { extraction, Gd }\end{array}$ & $\$ 2 \times 10^{7}$ & $0.1 \mathrm{l} / \mathrm{s}$ & $(\mathrm{PR})^{0.6}$ & $\begin{array}{l}17,400 \\
\mathrm{~kg} / 7000 \\
\mathrm{wppm} / 139 \mathrm{~d}\end{array}$ \\
\hline Volatility, $\mathrm{Xe}$ & $\$ 5 \times 10^{6}$ & $1000 \mathrm{l} / \mathrm{s}$ & $(\mathrm{PR})^{0.6}$ & $\begin{array}{l}0.017 \mathrm{~kg} / 0.7 \\
\mathrm{wppm} / 20 \\
\mathrm{~min} .\end{array}$ \\
\hline
\end{tabular}

A 140 day, $17,000 \mathrm{~kg}$ inventory of $\mathrm{Gd}$, for example at $880 \$ / \mathrm{kg}$, would be about $\$ 15 \mathrm{M}$. If Gd were important to have as a target material, a higher process rate would be important to minimize the inventory and therefore the cost of $\mathrm{Gd}$. Assuming that other costs, such as buildings and remote equipment, doubles the costs in Table 6 ( $40 \mathrm{M} \$$ direct for $\mathrm{Gd}$ ) and assuming an annual operating cost of 
0.12 times the capital cost (the plant averaged annual operating cost is assumed to be 0.06 times the direct cost of components, but the chemical separation plant will be more operations intensive), then we get $2.4 \mathrm{M} \$ / \mathrm{y}$ to process 39 tons of heavy high $\mathrm{Z}$ target material. Adding capital charges of $4 \mathrm{M} \$ / \mathrm{y}(10 \%$ of $40 \mathrm{M} \$)$ give a total direct annual cost of $6.4 \mathrm{M} \$$ or $164 \$ / \mathrm{kgHM}$ (HM= heavy metal). It would be about twice this for the rare earth lanthanides.

For comparison, $1200 \$ / \mathrm{kgHM}$ is a typical cost for aqueous processing of nuclear fuels and $\$ 350 \$ / \mathrm{kgHM}$ for pyroprocesses. Typical throughput of a plant to process the fuel from 20,1-GWe nuclear plants might be 100 tons/y for aqueous processing. A pyroprocessing plant is economical in sizes several times smaller. We can see the throughput of the processing plant to process target material and that to process fission fuel is comparable.

As stated earlier, adding $\mathrm{Gd}$ to the hohlraum material results in a $13.5 \%$ increase in gain. This would result in an approximate $4.7 \%$ decrease in cost of electricity for a $1 \mathrm{GWe}$ plant. This is equivalent to a $130 \mathrm{M} \$$ capital cost decrease $(65 \mathrm{M} \$$ direct). Said another way, the added cost to manufacture targets with Gd or some substitute (including recovery ready for remanufacturing) can cost up to $130 \mathrm{M} \$$ ( $65 \mathrm{M} \$$ direct cost). However, the cost cited above for $\mathrm{Gd}$ removal was $40 \mathrm{M} \$$ direct. Clearly, we should be concerned about the cost of using Gd.

The clear implication of the above process costs are the simplest, lowest cost process should be selected. Volatility of $\mathrm{Hg}$ should be used and $\mathrm{Gd}$ avoided. The extra yield from targets may not be worth the extra cost unless other more easily separable materials can be found.

The energy production per unit target material throughput is (1000 MWe/[0.25 g $\times 10^{-6}$ tons $/ \mathrm{g} \times 5.8 / \mathrm{s} \times 3600 \mathrm{~s} / \mathrm{hr} \times 24 \mathrm{hr} /$ day $\left.=\right) 8000 \mathrm{MWe}$-days $/$ ton. At 38.8 tons/y the annual cost of new material with no recycle would be, $337 \mathrm{k} \$, 580 \mathrm{k}$, $8.5 \mathrm{M}$, and $50 \mathrm{k}$, for $\mathrm{Hg}$ (costing $8.70 \$ / \mathrm{kg}), \mathrm{W}(15 \$ / \mathrm{kg}), \mathrm{Ta}(220 \$ / \mathrm{kg})$, and $\mathrm{Pb}$ $(\$ 1.30 / \mathrm{kg})$. Compared to the annual value of electricity produced of about 370 
$\mathrm{M}$ \$ we can see these costs are insignificant and recycle would only be employed for reasons other than cost of materials (e.g. to minimize radioactive waste inventory). By comparison gold at $350 \$ / \mathrm{oz}$ or $\$ 12,300 / \mathrm{kg}$ would cost $478 \mathrm{M} \$$ for a years supply with no recycle. Gd would be $\$ 40 \mathrm{M}$. We could use gold but would have to recycle it.

\section{Safety and environment considerations}

There are three main measures for the safety and environmental (S\&E) acceptability of target materials [Latkowski et al. Oct 2000 and Mar 2000]. First, an accident in the target fabrication facility, for example, must produce a site boundary $(1 \mathrm{~km})$ dose of less than $10 \mathrm{mSv}(1 \mathrm{rem})$, including any tritium release. Second, the large throughput of target material ( $\sim 50$ tonnes/year), suggests that materials must be selected so that they can be recycled. Third, it is desirable to select target materials that may be disposed of as Class $C$ (eligible for shallow land burial) waste at the end-of-life of the power plant. If, however, recycling is performed on a weekly basis, then it may be sensible to allow this material (volume $<0.1 \mathrm{~m}^{\wedge} 3$ ) to exceed the Class $\mathrm{C}$ limits. This issue is still under debate in the S\&E community.

\section{Alternatives to flibe systems}

Alternative liquids to flibe are lithium, lithium-lead $\left(\mathrm{Li}_{17} \mathrm{~Pb}_{83}\right)$, and tin-lithium $\left(\mathrm{Sn}_{80} \mathrm{Li}_{20}\right)$. Alternatives to flibe have a serious pumping power problem with a thick layer of liquid (Moir, 2000). Nevertheless, we include a discussion of alternatives. Design modifications might overcome the high pumping power of alternative liquids. $\mathrm{Hg}$ could be used with the alternatives. It is soluble and its high vapor pressure would allow easy separation by volatility process discussed above. $\mathrm{Pb}$ is also soluble in $\mathrm{Li}$ but its removal is not so easy. Centrifugation would be difficult because of the $\mathrm{Pb}$ is in solution rather than an immiscable heavy liquid. Selective freezing will not freeze out $\mathrm{Pb}$ because its freezing point is much higher than that of $\mathrm{Li}$. There is not much problem with letting the $\mathrm{Pb}$ 
simply accumulate until separation becomes practical by freezing out the $\mathrm{Li}$ in order to raise the concentration of $\mathrm{Pb}$ in the remaining liquid. Corrosion enhancement by the $\mathrm{Pb}$ additive must be considered.

In the case of $\mathrm{LiPb}$, the use of $\mathrm{Pb}$ in the targets would not even be a contaminant and no extraction would be needed. The use of $\mathrm{Hg}$, which is soluble in $\mathrm{LiPb}$, would allow easy separation by volatility if desired. Hg should also work with SnLi.

Separation of elements with $\mathrm{Z}$ about 15 lower than $\mathrm{Pb}$ or $\mathrm{Hg}$, i.e., the Lanthanides must be considered if target designs call for them. Their solubility is quite low in $\mathrm{Li}$ and $\mathrm{LiPb}$ (this needs to be confirmed) which might permit them to be easily removed by centrifugation for concentrations above their solubility limits.

\section{Conclusions}

A flibe coolant clean up and processing system has been described. The plant design and especially the target design need to take into account the process system. Target materials will need to be processed for recycle. Target fabrication needs to be considered when choosing target materials and processes. We are looking for practical materials to substitute for those used in present experiments, Au and Gd. A combination or "cocktail" of several materials might do the job. Many materials can be eliminated based on prohibitively expensive materials or processing steps. The favored materials are those that can be separated by the simple volatility process. There is a worry about using $\mathrm{Pb}$, which can be separated by centrifugation but attack of metal surfaces may be a feasibility problem. We recommend further studies to find a combination of three materials, each of which can be easily separated. $\mathrm{Hg}$, Xe and a third element as yet to be specified are recommended for target materials. Processing is needed for chemistry control of corrosion and target debris and impurity clean up. 


\section{Acknowledgments}

This work was performed under the auspices of the U.S. Department of Energy by University of California Lawrence Livermore National Laboratory under contract No. W-7405-Eng-48. Useful discussions with Dai-Kai Sze on equilibrium and Mel Coops on separation technology, J. Latkowski, Wayne Meier, D. Callahan-Miller and R. Petzoldt for numerous discussions about the paper are acknowledged.

\section{References}

D. A. Callahan-Miller and M. Tabak (2000), "Progress in target physics and design for heavy ion fusion," Physics of Plasmas 7 (2000) 2083-2091.

L. S. Chow, J. K. Basco, J. P. Ackerman, and T. R. Johnson (1993), “Continuous extraction of molten chloride salts with liquid cadmium alloys," Global 93, Int. Conf. and Technology exhibition future nuclear systems: emerging fuel cycles and wastes disposal options, Vol. 2 p 1080-1085 (1993?).

T. J. Dolan and G. R. Longhurst (1992), "A vacuum disengager for tritium removal from HYLIFE-II reactor flibe" Fusion Technology 21 1949-1954.

D. J. Fray (2000), "Separating rare earth elements," Science 29 (2000) 2295-2329.

P. A. House (1994), HYLIFE-II Reactor Chamber Design Refinements," Fusion Technology 26 1178-1195.

J. R. Keiser, J. H. DeVan, and E. J. Lawrence (1979), "Compatibility of Molten Salts with Type 316 Stainless Steel and Lithium," J. Nucl. Mater. 85-86, 295 (1979).

J. F. Latkowski et al., "Selection of IFE Target Materials from a Safety and Environmental Perspective," Presented at the Thirteenth International Symposium on Heavy Ion Inertial Fusion (Mar. 2000) and to appear in Nucl. Inst. and Meth. A.

J. F. Latkowski et al., "Preliminary Safety Assessment for an IFE Target Fabrication Facility," Presented at the ANS Fourteenth Topical Meeting on the Technology of Fusion Energy (Oct. 2000) and to appear in Fusion Technol

G. R. Longhurst and T. J. Dolan (1993), “HYLIFE-II tritium management system Idaho National Engineering Laboratory report EGG-FSP-9971. 
M. D. Lowenthal, E. Greenspan, R. Moir, W. E. Kastenberg, and T. K. Fowler (1998), Industrial ecology for inertial fusion energy selection of high-Z material for HYLIFE-II targets," Fusion Technology 34 (1998) 619-628.

R. W. Moir et al. (1994), “HYLIFE-II: A Molten-Salt Inertial Fusion Energy Power Plant Design-Final Report," Fusion Technology 25 5-25 (1994).

R. W. Moir (1996), "E Gads! Gadolinium added to the hohlraum will be too expensive," December 19, 1996.

R. W. Moir (1997), "flibe coolant cleanup and processing in the HYLIFE-II IFE plant," draft memo, February 24, 1997.

R. W. Moir (2000),"Liquid walls for fusion reaction chambers," Comments on Plasma Physics and Controlled Fusion, 2 (2000) 99-111.

J. H. Shaffer (1971), "Preparation and handling of salt mixtures for the molten salt reactor experiment," ORNL-4616 (Jan 1971). See especially p 7 to 9 for oxide removal.

Larry Suter (1996), private communications, 10/7/1996.

L. Suter, J. Rothenberg, D. Munro, B. Van Wonterghem, and S. Haan (2000), "Exploring the limits of the National Ignition Facility's capsule coupling," Physics of Plasmas 7 (2000) 2092-2098.

M. W. Rosenthal, P. N. Haubenreich and R. B Briggs (1972), “The development status of molten-salt breeder reactors," ORNL-4812 (1972). p 339 to 343.

J. S. Watson, W. R. Grimes, and D. E. Brashears (1985), "Cost of processing fuel from a molten salt, fusion/fission, hybrid reactor blanket," Fusion Technology 8 (1985) 2113-2120. 


$$
1
$$

